\title{
E2F1/SP3/STAT6 axis is required for IL-4-induced epithelial-mesenchymal transition of colorectal cancer cells
}

\author{
JIAOE CHEN ${ }^{1}$, CHAOJU GONG $^{2}$, HUIQIN MAO ${ }^{3}$, ZHAOYUN LI $^{4}$, ZEJUN FANG $^{5}$, QIANG CHEN $^{1}$, MIN LIN $^{5}$, \\ XIANG JIANG ${ }^{1}$, YANYAN HU ${ }^{5}$, WEI WANG ${ }^{5}$, XIAOMIN ZHANG ${ }^{6}$, XIANJUN CHEN $^{4}$ and HONGZHANG LI ${ }^{1}$ \\ ${ }^{1}$ Department of Gastroenterology, Sanmen People's Hospital of Zhejiang, Sanmen, Zheijiang 317100; \\ ${ }^{2}$ Xuzhou Key Laboratory of Ophthalmology, The First People's Hospital of Xuzhou, Xuzhou, Jiangsu 221002; \\ ${ }^{3}$ Ultrasonography Department, Sanmen People's Hospital of Zhejiang, Sanmen, Zheijiang 317100; \\ ${ }^{4}$ Clinical Laboratory, Taizhou Central Hospital, Taizhou University Hospital, Taizhou, Zheijiang 318000; \\ ${ }^{5}$ Central Laboratory; ${ }^{6}$ Pharmaceutical Preparation Section, Sanmen People's Hospital of Zhejiang, \\ Sanmen, Zheijiang 317100, P.R. China
}

Received January 16, 2018; Accepted May 23, 2018

DOI: 10.3892/ijo.2018.4429

\begin{abstract}
Colorectal cancer (CRC) is a type of cancer with a mortality rate among the highest worldwide owing to its high rate of metastasis. Therefore, inflammation-associated metastasis in the development of CRC is currently a topic of considerable interest. In the present study, the pro-inflammatory cytokine interleukin-4 (IL-4) was identified to promote the epithelial-mesenchymal transition (EMT) of CRC cells. However, the enhancing effect of IL-4 was more evident in HCT116 cells compared with in RKO cells. Accordingly, an increased expression level of STAT6 was observed in HCT116 cells compared with RKO cells. Further investigations identified that E2F1 was required for maintaining the level of signal transducer and activator of transcription 6 (STAT6) in HCT116 cells. Mechanistically, E2F1 induced specificity protein 3 (SP3) directly by binding to the promoter of the STAT6 gene and activating its transcription in CRC cells. As a result, phosphorylation-activated STAT6 increased the expression of several EMT drivers, including zinc finger E-box-binding homeobox (Zeb)1 and Zeb2, which serve a critical function
\end{abstract}

Correspondence to: $\operatorname{Dr}$ Xianjun Chen, Clincal Laboratory, Taizhou Central Hospital, Taizhou University Hospital, 999 Donghai Avenue, Economic Development Zone, Taizhou, Zheijiang 318000, P.R. China

E-mail: chenxj2074@tzzxyy.com

Dr Hongzhang Li, Department of Gastroenterology, Sanmen People's Hospital of Zhejiang, 171 Renmin Road, Sanmen, Zheijiang 317100, P.R. China

E-mail: smyylhz@163.com

Key words: colorectal cancer, epithelial-mesenchymal transition, interleukin-4, E2F1, specificity protein 3, signal transducer and activator of transcription 6 in IL-4-induced EMT. Rescue experiments further confirmed that IL-4-induced EMT relied on an intact E2F1/SP3/STAT6 axis in CRC cells. Finally, analysis of clinical CRC specimens revealed a positive correlation between E2F1, SP3 and STAT6. The ectopically expressed E2F1/SP3/STAT6 axis indicated a poor prognosis in patients with CRC. In conclusion, the E2F1/SP3/STAT6 pathway was identified to be essential for IL-4 signaling-induced EMT and aggressiveness of CRC cells.

\section{Introduction}

Colorectal cancer (CRC) is one of the most common causes of malignancy-associated mortality, and tumor metastasis is the predominant component that leads to disease recurrence and mortality in patients with CRC $(1,2)$. Previous studies have demonstrated that chronic intestinal inflammation such as inflammatory bowel disease is associated with the risk of CRC, and the inflammatory microenvironment around the tumor serves a central function in the development and progression of CRC (3-5). Various pro-inflammatory cytokines released by infiltrating immune cells and other cells in the microenvironment have been identified to induce CRC metastasis (6). In particular, among these cytokines, including interleukin (IL)-6, IL-8, IL-13 and IL-17 are involved in the pathogenesis of CRC metastasis (7-10). In addition, previous studies have focused on the overactivation of IL-4 signaling in association with CRC cell invasiveness and metastasis. In CRC cells expressing the IL-4 receptor (IL-4R), IL-4 stimulation downregulates the expression of the cell adhesion molecule epithelial (E-)cadherin, suggesting that the cytokine may be involved in the epithelial-mesenchymal transition (EMT) of CRC (11). Additionally, IL-4R $\alpha$ appears to promote CRC growth, and blockade of the IL-4R $\alpha$-IL-4 interaction decreases proliferation and increases apoptosis (12).

IL-4 initiates the signaling pathway by binding to IL-4R $\alpha$, triggering a cascade, including the activation of Janus kinase (JAK)1 and JAK3, which phosphorylates and dimerizes signal transducer and activator of transcription 6 (STAT6). 
Finally, STAT6 homodimers translocate to the nucleus and bind to the promoters of IL-4-responsive genes to induce various biological functions (13). Therefore, STAT6 mediates signal transduction and determines the cellular response to IL-4 stimulation. However, abnormal STAT6 activation induced by IL-4 promotes pro-metastatic processes including migration and invasion, proliferation, and survival in cancer cells. For example, in colorectal cancer stem cells (CR-CSCs), the IL-4/STAT6 signaling pathway helps cells to escape cell death by increasing the nuclear survivin pool (14). In addition, Liu et al (15) identified that the IL-4/STAT6 signaling pathway accelerates CRC cell proliferation through enhancing the expression of nicotinamide-adenine dinucleotide phosphate oxidase 1.

Although E2F1 is recognized as a strong apoptosis-driver following chemotherapy-induced DNA damage in all types of human cancer, evidence suggests that E2F1 is associated with cancer progression. Increased abundance of E2F1 in various cancer cells has been identified to trigger invasion and metastasis by activating cytokine receptor signaling pathways. In malignant melanoma, E2F1-dependent progression is mediated via upregulation of epidermal growth factor receptor (EGFR) and activation of the mitogen-activated protein kinase/extracellular-signal-regulated kinase and phosphoinositide 3-kinase/protein kinase B signaling cascades (16). Other evidence indicates that E2F1 transactivates integrin-linked kinase, which drives the IL-6/nuclear factor- $\kappa \mathrm{B}(\mathrm{NF}-\kappa \mathrm{B})$ signaling loop in triple-negative breast cancer (17). In our previous study, different expression levels of E2F1 were detected in several CRC cell lines, and knockdown of E2F1 was identified to impair the aggressive phenotypes of CRC cells with highly expressed E2F1 (18). Therefore, whether E2F1 contributes to CRC development promoted by inflammatory cytokines requires further investigation.

In the present study, a previously unknown function of E2F1 as an enhancer in the IL-4/STAT6 signaling pathway was identified. The results supported the hypothesis that E2F1 is able to induce STAT6 expression by upregulating specificity protein 3 (SP3), which was identified as a transcription activator of the STAT6 gene in CRC cells. An increase in total STAT6 protein led to a strong response to IL-4 stimulation, as indicated by a high level of STAT6 phosphorylation. Finally, as targets of the activated STAT6, zinc finger E-box-binding homeobox (Zeb)1 and Zeb2 boosted EMT and aggressiveness of CRC cells. Thus, the existence of an aberrant E2F1/SP3/STAT6 axis may amplify the IL-4 signaling which facilitates CRC metastasis.

\section{Materials and methods}

Cell lines and culture. Human CRC cell lines SW480, HCT116, RKO, HT-29 and DLD1 were purchased from the American Type Culture Collection (Manassas, VA, USA). The cells were cultured and stored according to the supplier's protocol. In detail, all the cells were cultured in RPMI-1640 medium supplemented with $10 \%$ fetal bovine serum (FBS; Gibco; Thermo Fisher Scientific, Inc., Waltham, MA, USA) at $37^{\circ} \mathrm{C}$ in a humidified atmosphere containing $5 \% \mathrm{CO}_{2}$. Cell passage was performed every 2 days. Short hairpin RNA targeting E2F1 (shE2F1, 5'-CUGCAGAGCAGAUGGUUAU-3'; GenePharma,
Shanghai, China)-stably transfected HCT116 cells were derived from the parental cells using G418 (Sigma-Aldrich; Merck KGaA, Darmstadt, Germany) selection. Human recombinant IL-4 (R\&D Systems, Minneapolis, MN, USA) at $20 \mathrm{ng} / \mathrm{ml}$ was used to treat CRC cells. Cell morphology was visualized by phase-contrast microscopy (magnification, $\mathrm{x} 400$ ).

Reagents and antibodies. Recombinant human IL-4 was purchased from PeproTech, Inc. (Rocky Hill, NJ, USA). Antibodies against E-cadherin (cat. no. sc-7870; 1:1,000), vimentin (cat. no. sc-6260; 1:1,000), E2F1 (cat.no. sc-193; 1:1,000) and GAPDH (cat. no. sc-365062; 1:5,000) were purchased from Santa Cruz Biotechnology, Inc. (Dallas, TX, USA). Antibodies against zonula occludens-1 (ZO-1; cat. no. ab59720; 1:500), fibronectin (cat. no. ab2413; 1:1,000) and SP3 (cat. no. ab129099; 1:1,000) were purchased from Abcam (Cambridge, UK). Antibodies against phosphorylated (p-)JAK1 (cat. no. 3331; 1:500), JAK1 (cat. no. 3332; 1:1,000), p-STAT6 (cat. no. 9361; 1:500) and STAT6 (cat. no. 9362; 1:1,000) were purchased from Cell Signaling Technology, Inc. (Danvers, MA, USA).

Reverse transcription-quantitative polymerase chain reaction (RT-qPCR) analysis. Total RNA was isolated from the CRC cell lines (HCT116, RKO, HT-29 or DLD1) with RNAiso Plus (Takara Bio, Inc., Otsu, Japan), according to the manufacturer's protocol. RNA quality and concentration was evaluated using a NanoDrop ND-1000 spectrophotometer. A total of $0.5 \mu \mathrm{g}$ RNA was reverse-transcribed using a cDNA Reverse Transcription kit (Takara Bio, Inc.), according to the manufacturer's protocol. The resulting cDNA was analyzed in triplicate using qPCR $\left(95^{\circ} \mathrm{C}\right.$ for $5 \mathrm{~min}$, followed by 40 cycles of $95^{\circ} \mathrm{C}$ for $45 \mathrm{sec}$, annealing at $55^{\circ} \mathrm{C}$ for $45 \mathrm{sec}$ and extension at $72^{\circ} \mathrm{C}$ for $1 \mathrm{~min}$ ) on a Step One Plus Real-Time PCR system (Thermo Fisher Scientific, Inc.) with SYBR-Green Master Mix (Roche Diagnostics, Basel, Switzerland), according to the manufacturer's protocol. Target gene expression was normalized to GAPDH levels in respective samples as an internal control and calculated using the $2^{-\Delta \Delta \mathrm{Cq}}$ method (19). The sequences of the qPCR primers are listed in Table I.

Western blotting. Cells were harvested and lysed using radioimmunoprecipitation lysis buffer [50 mM Tris/ $\mathrm{HCl}, \mathrm{pH} 7.4$, $100 \mathrm{mM}$ 2-mercaptoethanol, 2\% (w/v) SDS and 10\% glycerol]. The protein concentration was determined using the Bradford method (Bio-Rad Laboratories, Inc., Hercules, CA, USA). The proteins (40 $\mu \mathrm{g} /$ lane) were separated by SDS-PAGE (10 gels) and transferred onto nitrocellulose membranes (Whatman, Maidstone, UK). The membrane was blocked with $5 \%$ non-fat milk powder (diluted in Tris-buffered saline with Tween-20) for $2 \mathrm{~h}$ at room temperature and then incubated with diluted primary antibodies followed by IRDye ${ }^{\circledR}$ 800CW- or IRDye 680RD-conjugated secondary antibodies (LI-COR Biosciences, Lincoln, NE, USA): IRDye 680RD goat anti-rabbit immunoglobulin $\mathrm{G}$ ( $\mathrm{IgG}$ ) [heavy and light chains $(\mathrm{H}+\mathrm{L})$ ] (cat. no. 926-68071), IRDye 800CW goat anti-rabbit IgG $(\mathrm{H}+\mathrm{L})$ (cat. no. 926-32211), IRDye 680RD goat antimouse IgG $(\mathrm{H}+\mathrm{L})$ (cat. no. 926-68070) and IRDye 800CW goat anti-mouse $\operatorname{IgG}(\mathrm{H}+\mathrm{L})$ (cat. no. 926-32210). All the secondary antibodies were diluted at 1:20,000, and detection 
Table I. Sequences of qPCR primer pairs.

\begin{tabular}{lll} 
Gene & \multicolumn{1}{c}{ Forward primer $\left(5^{\prime}-3^{\prime}\right)$} & \multicolumn{1}{c}{ Reverse primer $\left(5^{\prime}-3^{\prime}\right)$} \\
\hline STAT6 & AGGTGTACCCACCACACTCT & GGTCACATCTGAGCAGAGCA \\
Slug & CAGTATGTGCCTTGGGGGAG & AGGCACTTGGAAGGGGTATTG \\
Zeb1 & AGAGCGCTAGCTGCCAATAA & GGGCGGTGTAGAATCAGAGT \\
Zeb2 & GGCCTACACCTACCCAACTG & ACAGGAGTCGGAGTCTGTCA \\
Snail1 & CCTGTCTGCGTGGGTTTTTG & ACCTGGGGGTGGATTATTGC \\
Twist1 & GCATTCTCAAGAGGTCGTGC & GGTTTTCAGGCCAGTTTGAT \\
\hline
\end{tabular}

STAT6, signal transducer and activator of transcription 6; Zeb, zinc finger E-box-binding homeobox.

was performed using the Odyssey Infrared Imaging System (LI-COR Biosciences, Lincoln, NE, USA). The obtained signals were converted into grayscale images (Application Software, version 2.1.12; LI-COR Biosciences).

Luciferase assay. In total, $1 \times 10^{5}$ HCT116 cells were plated onto 24-well plates. The next day, cells were co-transfected with firefly luciferase reporter constructs and pRL-SV40 Renilla luciferase reporter plasmids (Promega Corporation, Madison, WI, USA). The pRL-SV40 plasmid was used to normalize the transfection efficiency. The luciferase activities were measured using a dual-luciferase reporter assay system (Promega Corporation) and a luminometer (LB 9507; Berthold Technologies GmbH and Co. KG, Bad Wildbad, Germany). All experiments were performed in triplicate.

Chromatin immunoprecipitation (ChIP). Chromatin was crosslinked with $1 \%$ formaldehyde and ChIP assays were performed using a SimpleChIP ${ }^{\circledR}$ Enzymatic Chromatin IP kit (Cell Signaling Technology, Inc.; cat. no. 9003), according to the manufacturer's protocol. The immunoprecipitated DNA fragments were quantified using RT-qPCR using the following primer pairs for the STAT6 promoter: -1,300 bp, 5'-TGGTTAGCAGCATTAGC AGG-3' (forward) and 5'-CAGCTCCTCCTCCTCCATCC-3' (reverse); -400 bp, 5'-TCAGTCCAAGGGACTCCTAG-3' (forward) and 5'-GCTCGATGCCAGCCAACTCC-3' (reverse); +500 bp, 5'-GGTTTCAGCTAGTGTTGGTG-3' (forward) and 5'-GAGGGGCACTCCTTCACCTC-3' (reverse).

Wound healing assay. Cells were seeded in 6-well plates. Following transfection for $24 \mathrm{~h}$, the monolayer was gently and slowly scratched with a pipette tip across the center of the well. Following scratching, the well was gently washed several times with PBS to remove the detached cells. The wells were replenished with fresh medium without serum, and the cells were allowed to grow for an additional $48 \mathrm{~h}$, and the images of the stained monolayer were captured at $\mathrm{x} 40$ magnification under a light microscope (Eclipse Ti, Nikon, Kyoto, Japan). The wound was evaluated using ImageJ (version 1.4.3.67; National Institutes of Health, Bethesda, MD, USA).

Cell invasion assays. Cell invasion was assessed in Boyden chambers with Matrigel (Invitrogen; Thermo Fisher Scientific, Inc.), according to the manufacturer's protocol. First, an 8-mm-porosity polycarbonate membrane was covered with $200 \mu 1$ serum-free medium containing $1 \times 10^{5}$ cells/well. The plates were then incubated with $10 \% \mathrm{FBS}$ for $48 \mathrm{~h}$ at $37^{\circ} \mathrm{C}$ in a humidified atmosphere containing $5 \% \mathrm{CO}_{2}$. The invading cells on the lower surface of the filter were fixed, stained and counted under a light microscope (Eclipse Ti) at x100 magnification.

Xenografts. Animal experiments were performed with the approval of the Ethics Committee of Sanmen People's Hospital (Sanmen, China) and the Animal Care and Use Committee of Zhejiang University (Hangzhou, China). A total of 28 female BALB/c nude mice (5-week-old; weight, $18 \mathrm{~g}$; housed at $25^{\circ} \mathrm{C}$ with filtered air by efficiency particulate air filters with $40-60 \%$ humidity on a 10-h light/14-h dark cycle, with; free access to food and water) were purchased from the Laboratory Animal Center of Zhejiang University and randomly divided into HCT116/shCtrl, IL-4-HCT116/shCtrl, HCT116/shE2F1 and IL-4-HCT116/shE2F1 groups ( $n=7$ per group), where shCtrl is control short hairpin RNA (5'-UUC UCCGAACGUGUCACGU-3'; GenePharma, Shanghai, China), and equal amounts of indicated cells $\left(5 \times 10^{6}\right)$ were injected subcutaneously into each mouse. IL-4 was administered by intraperitoneal injection at a dose of $10 \mu \mathrm{g} / \mathrm{kg}$ three times weekly for 2 weeks. Treatment began on day 7, when the tumor sizes were measurable. The tumors were examined every 2 days, the length and width measurements were obtained with calipers, and the tumor volumes were calculated. On day 21, the animals were euthanized using decapitation under Midazolam anesthesia (5 mg/kg), and the tumors were excised and weighed. The IL-4/STAT6 signaling in the tumor tissues was analyzed by immunohistochemistry.

Immunohistochemistry. Experiments using human tissues were performed with the approval of the Ethics Committee of Sanmen People's Hospital. In total, 218 human CRC samples were collected at Sanmen People's Hospital, and written informed consent was obtained from all patients. Immunohistochemistry was performed and analyzed as described in our previous study (20).

Statistical analysis. Statistical analysis was performed with SPSS software (version 22.0; IBM Corp., Armonk, NY, USA) and GraphPad Prism (version 5.0; GraphPad Software, Inc., 
A

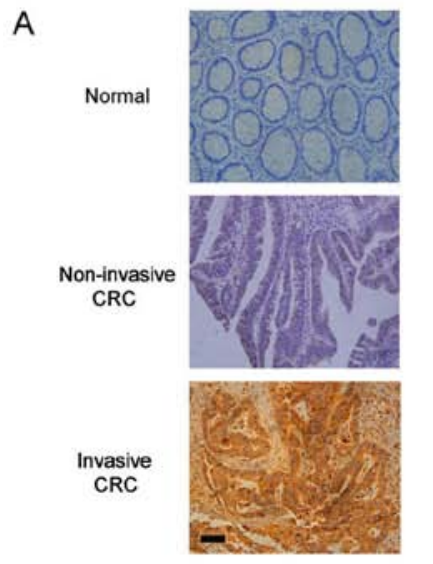

C

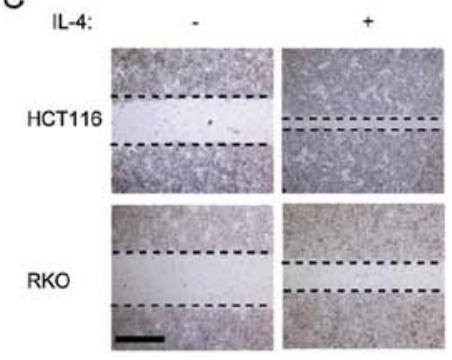

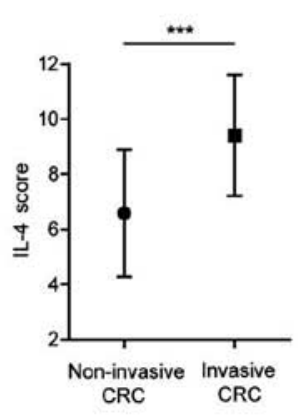

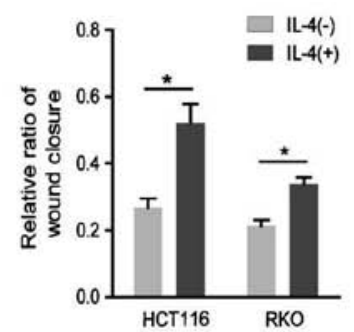

B

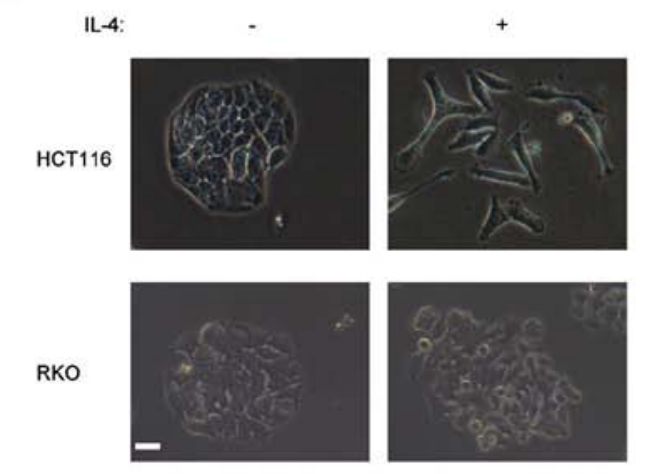

D

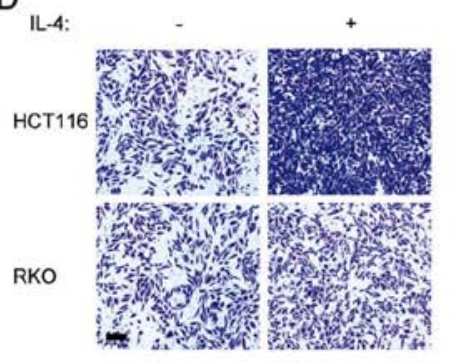

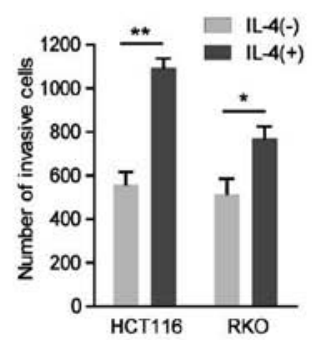

$\mathrm{F}$

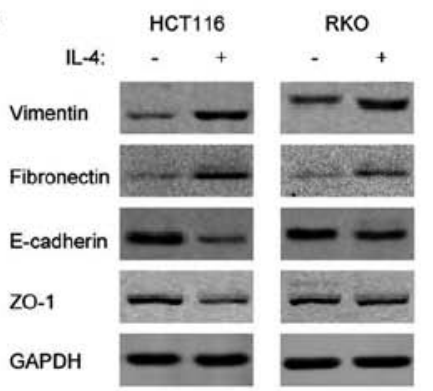

$\mathrm{E}$ HCT116
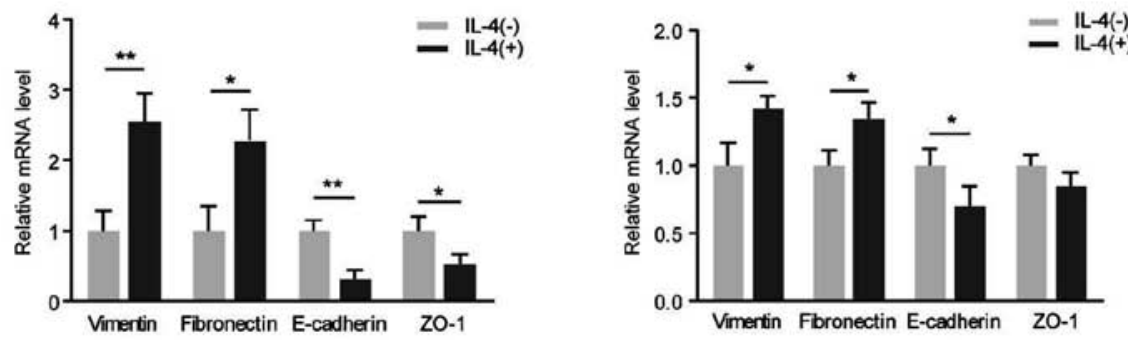

$=\stackrel{I-4(-)}{1 L-4(+)}$

Figure 1. IL-4-induced epithelial-mesenchymal transition program is more evident in HCT116 cells compared with in RKO cells. (A) Left: Representative images of IL-4 immunostaining in human colorectal cancer tissue and para-tumor tissue. Scale bar, $200 \mu \mathrm{m}$. Right: Immunostaining scores of IL-4 in invasive or non-invasive CRC tissues. (B) Morphology of HCT116 and RKO cells treated with or without IL-4 (20 ng/ml) for $72 \mathrm{~h}$ visualized using phase-contrast microscopy. Scale bar, $500 \mu \mathrm{m}$. (C) Left: Representative images from wound healing assays with HCT116 and RKO cells treated with $20 \mathrm{ng} / \mathrm{ml} \mathrm{IL-4.} \mathrm{Scale}$ bar, $100 \mu \mathrm{m}$. Right: Percentage wound closure $48 \mathrm{~h}$ after addition of IL-4. (D) Left: Representative images of HCT116 and RKO cells penetrating the Matrigel in invasion assays following treatment with $20 \mathrm{ng} / \mathrm{ml} \mathrm{IL}-4$. Scale bar, $100 \mu \mathrm{m}$. Right: numbers of invasive cells treated with IL-4 for $48 \mathrm{~h}$. (E) Relative mRNA levels of vimentin, fibronectin, E-cadherin and ZO-1 in HCT116 (left) and RKO (right) cells treated with $20 \mathrm{ng} / \mathrm{ml} \mathrm{IL-4} \mathrm{for} 48 \mathrm{~h}$. (F) Western blots of vimentin, fibronectin, E-cadherin and ZO-1 with specific antibodies in HCT116 (left) and RKO (right) cells treated with $20 \mathrm{ng} / \mathrm{ml} \mathrm{IL}-4$ for $48 \mathrm{~h}$. " P<0.05; "* P<0.01. IL, interleukin; CRC, colorectal cancer; E-cadherin, epithelial cadherin; ZO-1, zonula occludens-1.

La Jolla, CA, USA). Analysis of differences was performed using a two-tailed Student's t-test and analysis of variance (one-way with Tukey's post hoc test; two-way with Sidak's post hoc test). The results are presented as the mean \pm standard deviation of three separate experiments. $\chi^{2}$ test or Fisher's exact probability test was used to compare the clinicopathological features of the patients with protein expression. A Spearman's rank correlation test was used for analyzing the correlation. Kaplan-Meier plots and log-rank tests were used for survival analysis. $\mathrm{P}<0.05$ was considered to indicate a statistically significant difference.

\section{Results}

IL-4-induced EMT is more evident in the CRC cell line HCT116 compared with the RKO. Although expression of IL-4 and
IL-4R is involved in the process of local metastases in colorectal cancer (21), the underlying molecular mechanisms have not been clearly elucidated. In the present study, IL-4 immunoreactivity was observed in clinical CRC tissues, but not in adjacent normal tissues, and a higher IL-4 level was detected in invasive CRC tissues compared with in non-invasive ones (Fig. 1A). Additionally, IL-4 was identified to induce an EMT-like morphological change in CRC cells (Fig. 1B). The potential function of IL-4 in EMT induction in CRC cells was investigated. Following exogenous IL-4 stimulation, the migration of HCT116 and RKO cells was identified to be increasing, and the CRC cells exposed to IL-4 also acquired the capacity for migration and invasion (Fig. 1C and D). Furthermore, IL-4 treatment decreased the expression of the membranous epithelial marker E-cadherin and increased the expression of the cytoplasmic mesenchymal marker vimentin at the mRNA and protein levels in HCT116 
A

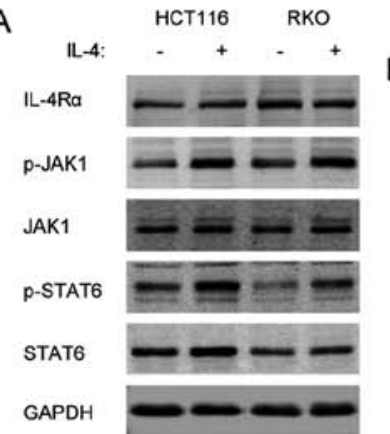

B

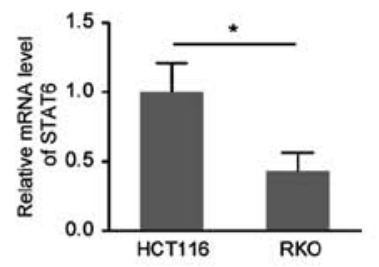

C

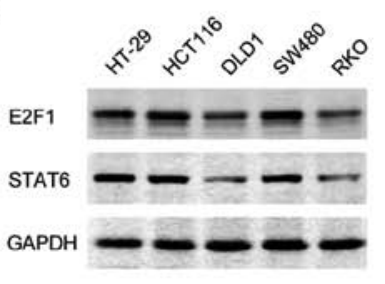

D

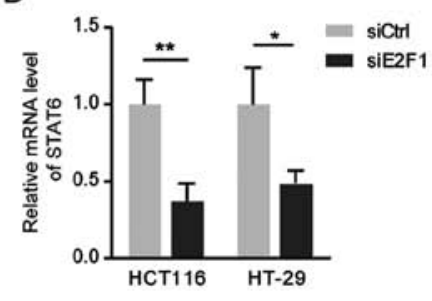

$\mathrm{E}$

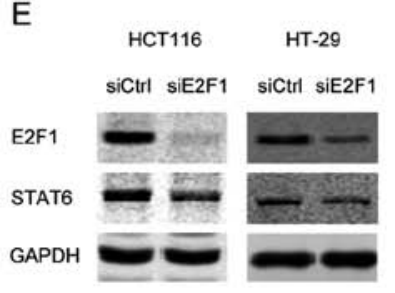

$\mathrm{F}$

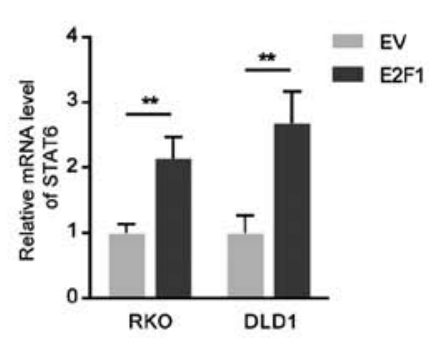

G

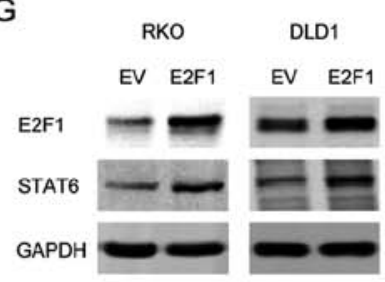

HCT116

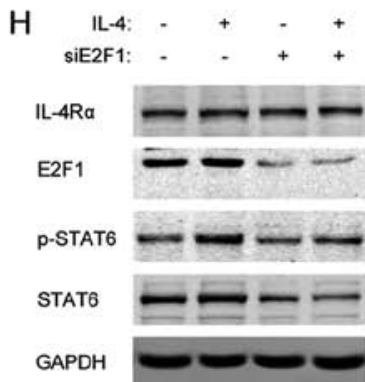

Figure 2. Constitutive expression of STAT6 is dependent on E2F1 in CRC cells. (A) Western blots of the indicated proteins with specific antibodies in HCT116 (left) and RKO (right) cells exposed to $20 \mathrm{ng} / \mathrm{ml} \mathrm{IL-4} \mathrm{for} 12 \mathrm{~h}$. (B) Relative mRNA levels of STAT6 in HCT116 and RKO cells (normalized to GAPDH). (C) Expression of E2F1 and STAT6 proteins in 5 CRC cell lines was analyzed by western blotting. (D) mRNA and (E) protein levels of STAT6 in HCT116 and HT-29 cells with knockdown of E2F1. (F) mRNA and (G) protein levels of STAT6 in RKO and DLD1 cells with E2F1 overexpression. (H) Western blots of the indicated proteins with specific antibodies in HCT116 cells with E2F1 knockdown and treatment with 20 ng/ml IL-4. *P<0.05; ${ }^{* *}$ P $<0.01$. STAT6, signal transducer and activator of transcription 6; CRC, colorectal cancer; IL, interleukin; IL-4R $\alpha$, IL-4 receptor $\alpha$; p-, phosphorylated; JAK1, Janus kinase 1; si, small interfering RNA; Ctrl, control; EV, empty vector.

and RKO cells (Fig. 1E and F). In addition, repression of ZO-1 accompanied by the induction of fibronectin was observed in IL-4-treated HCT116 and RKO cells (Fig. 1E and F). However, it is notable that IL-4 exposure led to an increased EMT change in HCT116 cells compared with in RKO cells.

Constitutive expression of STAT6 is dependent on E2F1 in CRC cells. To understand the different responses to IL-4 in HCT116 and RKO cells, the IL-4/STAT6 signaling pathway was investigated in the two CRC cell lines. As presented in Fig. 2A, exogenous IL-4 resulted in a marked increase in p-STAT6 in HCT116, but not in RKO, cells due to a high level of STAT6 protein in HCT116 cells. Consistently, the mRNA level of STAT6 was significantly increased in HCT116 cells compared with in RKO cells (Fig. 2B). Furthermore, the expression levels of STAT6 were paralleled with those of E2F1 in different CRC cell lines (Fig. 2C). Small interfering (siRNA)-mediated E2F1 knockdown markedly decreased STAT6 expression at the mRNA (Fig. 2D) and protein (Fig. 2E) levels in HCT116 and HT-29 cells, and STAT6 was identified to be markedly upregulated following overexpression of E2F1 in RKO and DLD1 cells (Fig. 2F and G). As expected, the induced activation of IL-4/STAT6 signaling was blunted in the E2F1-silenced HCT116 cells, which exhibited attenuated STAT6 expression (Fig. 2H). From these results, it may be concluded that ectopically expressed E2F1 is required for the abnormal activation of IL-4/STAT6 signaling in CRC cells.

E2F1-induced SP3 transactivates STAT6 in CRC cells. Considering E2F1 is a well-known transcriptional activator, serial deletion constructs of the STAT6 gene promoter were examined using luciferase reporter assays to identify the transcriptional regulatory region responsive to E2F1 in HCT116 cells. It was identified that the STAT6 promoter without the region between -500 and -350 lost the ability to respond to E2F1 silencing (Fig. 3A). However, ChIP-PCR analysis revealed no enrichment of E2F1 protein into the STAT6 promoter (Fig. 3B). The promoter sequence $(-500 /-350)$ was analyzed and two potential GT-box elements predicted to be bound by SP3 were identified (Fig. 3C). Mutations in either the GT\#1 or GT\#2 sites decreased the reporter activity of the STAT6 gene promoter in HCT116 cells, and knockdown of SP3 mimicked the effect of these mutations (Fig. 3D and E). In turn, SP3 overexpression induced the reporter activity of the wild-type STAT6 promoter, but failed to induce the GT\#1/2-mutated STAT6 promoter (Fig. 3F). Consistently, the mRNA level of STAT6 was decreased following knockdown of SP3 in HCT116 cells (Fig. 3G). ChIP-PCR analysis also confirmed that SP3 directly bound to the STAT6 promoter at $\sim-400 \mathrm{bp}$, upstream of the transcription start site (Fig. 3H). Furthermore, E2F1 knockdown diminished the expression of SP3 and overexpression of SP3 rescued the attenuated STAT6 expression that resulted from E2F1 deprivation, indicating that SP3 mediates the E2F1-dependent increased level of expression of STAT6 in CRC cells (Fig. 3I).

Highly expressed E2F1 promotes the IL-4-induced aggressiveness by upregulating STAT6. On the basis of the aforementioned results, the function of E2F1 in the IL-4/STAT6 signalinginduced EMT process was next investigated. In IL-4-stimulated 

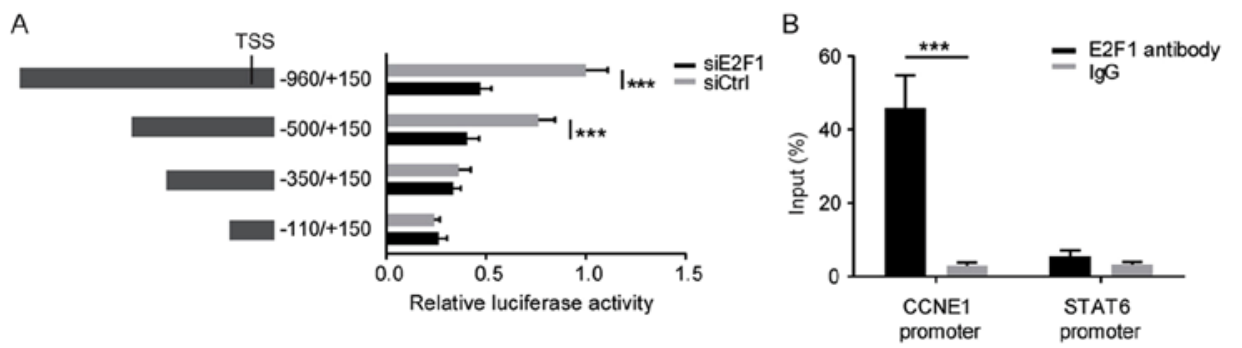

C

D

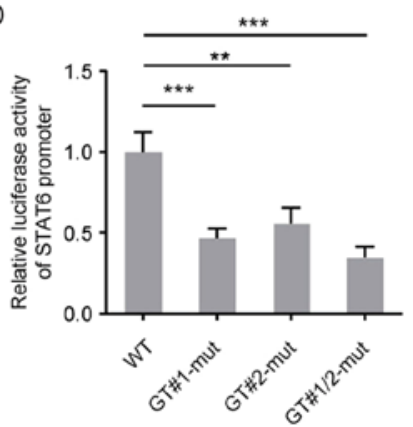

G

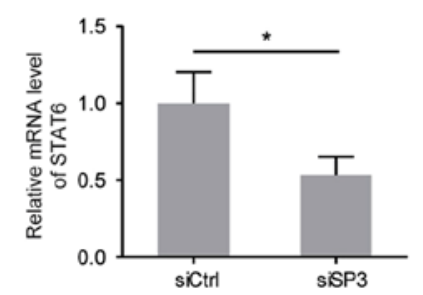

E

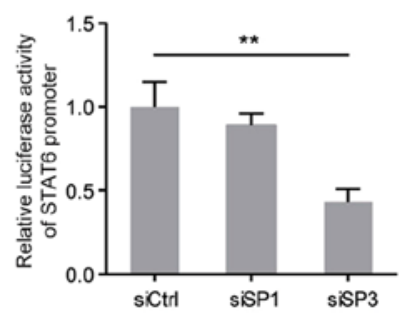

H

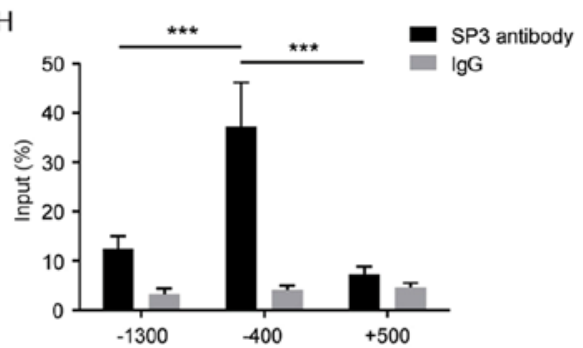

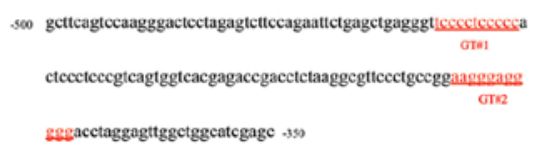

F

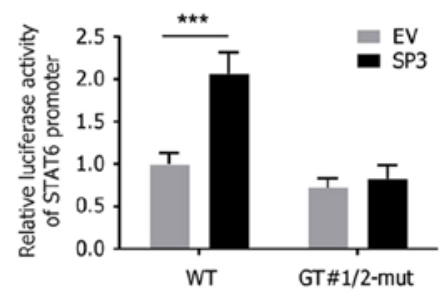

I

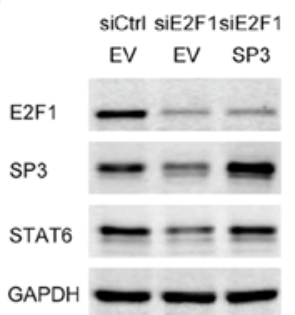

Figure 3. E2F1-induced SP3 transactivates STAT6 in CRC cells. (A) Relative luciferase activities were measured with a series of truncated constructs of the STAT6 promoter in HCT116 cells with E2F1 knockdown (internal control, pRL-SV40). (B) HCT116 cells were analyzed by ChIP assays using anti-E2F1 antibody and IgG. qPCR was performed with the immunoprecipitated DNA or soluble chromatin using the specific primer pairs for STAT6 promoter ( - 400 bp). CCNE1 served as a positive control. (C) The STAT6 promoter region (-500/-350) with two potential GT-box elements. (D) Relative luciferase activities in HCT116 cells transfected with the wild-type or GT-box-mutated STAT6 promoter reporter constructs. (E) Relative luciferase activity of STAT6 promoter in HCT116 cells with knockdown of SP1 or SP3. (F) Relative luciferase activity of the wild-type or GT-box-mutated STAT6 promoter in HCT116 cells with overexpression of SP3. (G) mRNA level of STAT6 in HCT116 cells with SP3 knockdown. (H) HCT116 cells were analyzed by ChIP assays using anti-SP3 antibody and IgG. qPCR was performed with the immunoprecipitated DNA or soluble chromatin using the specific primer pairs for STAT6 promoter regions $(\sim-1300,-400$ and +500 bp). (I) Western blots of the indicated proteins with specific antibodies in HCT116 cells with E2F1 knockdown and SP3 overexpression. ${ }^{*} \mathrm{P}<0.05 ;{ }^{* *} \mathrm{P}<0.01 ;{ }^{* * *} \mathrm{P}<0.001$. SP3, specificity protein 3; STAT6, signal transducer and activator of transcription 6; CRC, colorectal cancer; ChIP, chromatin immunoprecipitation; IgG, immunoglobulin G; qPCR, quantitative polymerase chain reaction; TSS, transcription start site; si, small interfering RNA; Ctrl, control; CCNE1, cyclin E1; WT, wild-type; mut, mutant; EV, empty vector.

HCT116 cells, a decrease in a mesenchymal marker (vimentin) and an increase in epithelial markers (E-cadherin and ZO-1) were observed following knockdown of E2F1, whereas overexpression of STAT6 partially recovered the mesenchymal phenotype (Fig. 4A). In addition, the acquisition of migratory and invasive capabilities in HCT116 cells exposed to IL-4 was attenuated by E2F1 silencing, but restored when STAT6 was overexpressed (Fig. 4B). Similarly, overexpression of E2F1 enhanced the promoting effect of IL-4 on the mesenchymal phenotype in RKO cells; however, knockdown of STAT6 impaired the E2F1-dependent EMT properties (Fig. 4C). As expected, E2F1 overexpression strengthened the IL-4-induced migration and invasion of RKO cells, but failed to disrupt STAT6 (Fig. 4D). These results demonstrate that the regulation of STAT6 by E2F1 is essential for IL-4-induced malignancy in CRC cells.

As a target gene of STAT6, Zeb1 is important in IL-4 triggered$E M T$. Cao et al (22) identified that the IL-13/STAT6/Zeb1 pathway serves a critical function in promoting EMT and aggressiveness of CRC cells. The alterations in EMT-associated transcription factors including Snaill, Slug, Zeb1, Zeb2 and Twist1 in response to IL-4/STAT6 signaling were investigated. As presented in Fig. 5A and B, the mRNA and protein levels of Zeb1 and Zeb2 were markedly increased in HCT116 cells following IL-4 stimulation. However, in HCT116 cells with STAT6 knockdown, IL-4 was not able to induce Zeb1 and Zeb2 (Fig. 5C and D). Furthermore, it was identified that knockdown of STAT6 prevented IL-4 from inducing Zeb1 and EMT markers, whereas ectopic expression of Zeb1 recovered the cell's EMT properties (Fig. 5E). Therefore, consistent with a previous study (22), Zeb1 functions as a critical downstream effector of IL-4/STAT6 signaling during EMT process.

E2F1 is required for IL-4-induced CRC tumorigenesis in vivo. To further determine the involvement of E2F1 in IL-4-induced tumorigenesis, HCT116 cells with stable knockdown of E2F1 were constructed and subcutaneously injected into nude mice. Tumor formation was evaluated during the 21 days after injection. It was identified that IL-4 significantly promoted the 

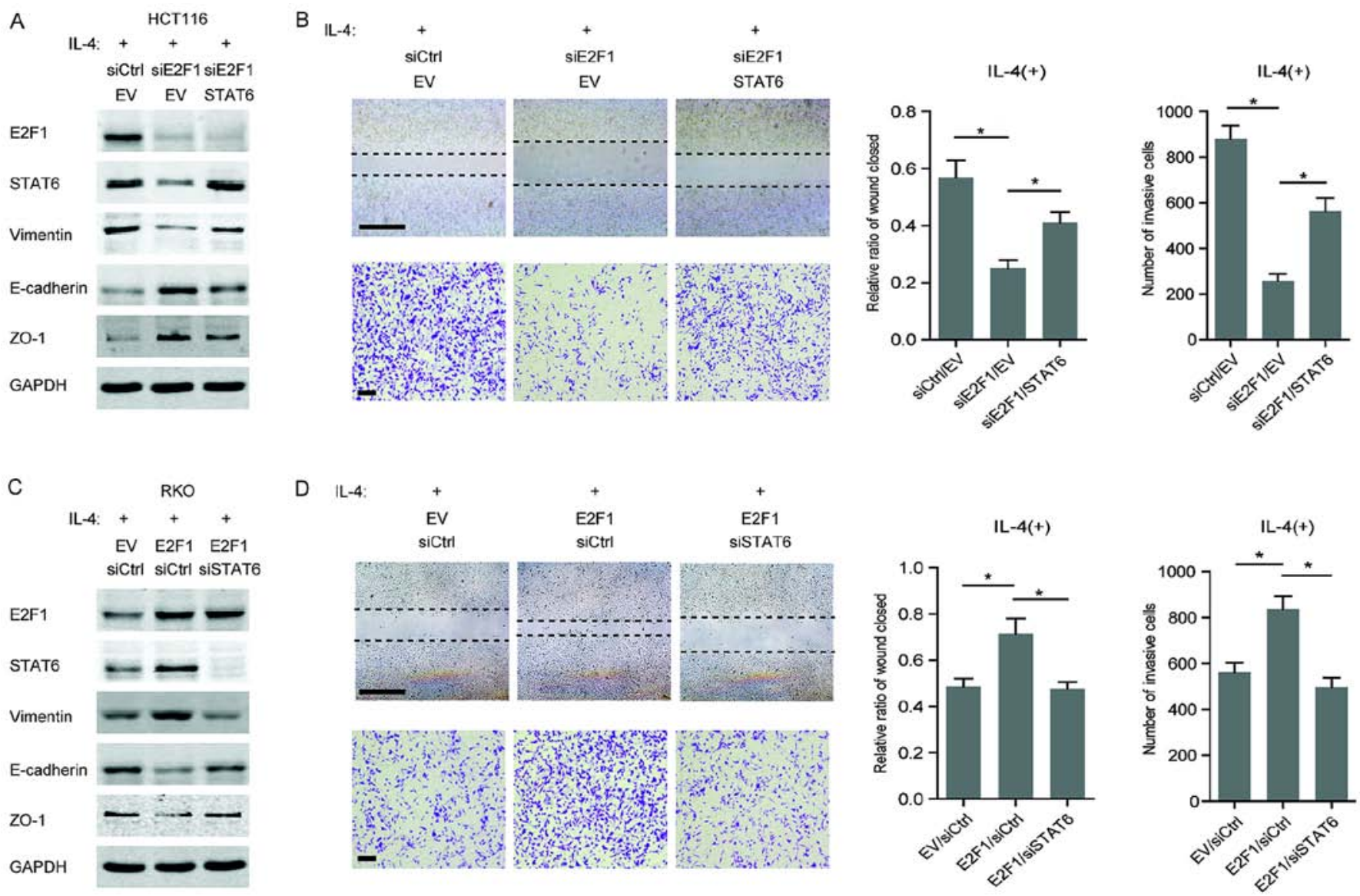

Figure 4. Highly expressed E2F1 promotes IL-4-induced aggressiveness by upregulating STAT6. (A) Western blots of the indicated proteins with specific antibodies in HCT116 cells co-transfected with E2F1 siRNA/STAT6 overexpression plasmid and exposed to $20 \mathrm{ng} / \mathrm{ml} \mathrm{IL-4} \mathrm{for} 48 \mathrm{~h}$. (B) Left: Representative images from wound healing and invasion assays with HCT116 cells co-transfected with E2F1 siRNA/STAT6 overexpression plasmid and exposed to $20 \mathrm{ng} / \mathrm{ml}$ IL-4 for $48 \mathrm{~h}$. Scale bar, $100 \mu \mathrm{m}$. Right: Percentage wound closure and numbers of invasive cells $48 \mathrm{~h}$ after IL-4 addition. (C) Western blots of the indicated proteins with specific antibodies in the RKO cells co-transfected with STAT6 siRNA/E2F1 overexpression plasmid and exposed to $20 \mathrm{ng} / \mathrm{ml} \mathrm{IL}-4$ for $48 \mathrm{~h}$. (D) Left: representative images from wound healing and invasion assays with the RKO cells co-transfected with STAT6 siRNA/E2F1 overexpression plasmid and exposed to $20 \mathrm{ng} / \mathrm{ml} \mathrm{IL-4}$ for $48 \mathrm{~h}$. Scale bar, $100 \mu \mathrm{m}$. Right: Percentage wound closure and numbers of invasive cells $48 \mathrm{~h}$ after IL- 4 addition. " $\mathrm{P}<0.05$. IL, interleukin; STAT6, signal transducer and activator of transcription 6; si, small interfering RNA; Ctrl, control; EV, empty vector; E-cadherin, epithelial cadherin; ZO-1, zonula occludens-1.

tumorigenesis of HCT116 cells, but not HCT116 cells with stable knockdown of E2F1 (Fig. 6A and B). Consistent with these results, immunostaining for the xenograft indicated that silencing of E2F1 inhibited IL-4-induced accumulation of p-STAT6 through decreasing the total STAT6 level (Fig. 6C). Thus, in vivo experiments suggest that E2F1 may exert a crucial function in IL-4-induced CRC tumorigenesis by regulating STAT6 signaling.

Abnormal activation of E2F1/SP3/STAT6 axis is associated with cancer aggressiveness in CRC samples. Immunohistochemical staining was performed to evaluate the protein levels of E2F1, SP3, STAT6 and p-STAT6 in human CRC specimens. As presented in Fig. 7A, different immunoreactivity intensities of E2F1, SP3, STAT6 and p-STAT6 were observed in CRC specimens. Further analysis revealed that all three factors were significantly correlated with the TNM stage and distant metastasis, but not with other clinical characteristics (Table II). In addition, immunostaining using consecutive sections revealed a positively correlation of the expression levels of STAT6 with the levels of E2F1 and SP3 (Fig. 7B and C). The potential associations between immunostaining and overall survival were retrospec- tively evaluated in 218 patients with CRC. A Kaplan-Meier analysis identified that increased expression of E2F1, SP3 or STAT6 significantly indicated poor survival (Fig. 7D-F). These results suggested that the E2F1/SP3/STAT6 axis is involved in CRC progression and metastasis.

\section{Discussion}

It is well-accepted that cytokines including ILs produced by tumor cells or, more often, by the B- or T-lymphocytes recruited to the tumor microenvironment promote the proliferation of tumor cells, perturb their differentiation and support the metastasis of cancer cells (23). Several lines of evidence suggest that IL-4 may suppress cancer-directed immunosurveillance and enhance tumor metastasis. For example, IL-4 has the ability to exert an autocrine proliferation stimulation effect in pancreatic cancer cells and furthermore serves paracrine functions on the surrounding infiltrating immune cells, repressing immunoresponses (24). In addition, it has been observed that secretion of IL-4, for instance, by malignant cells from the bladder, lung and colon, confers resistance to chemotherapy-induced cell death $(25,26)$. Particularly for 
A

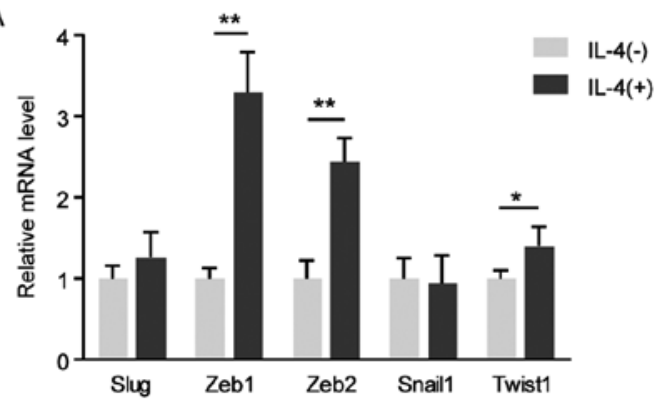

C

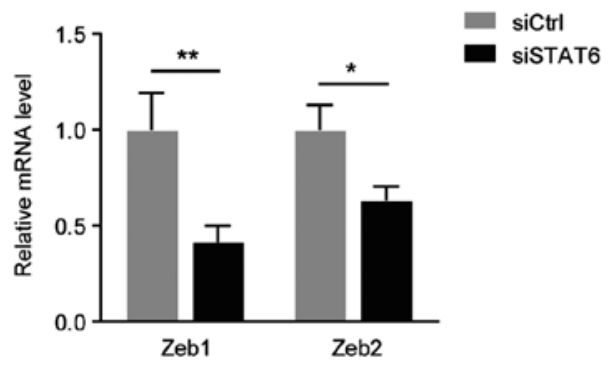

D

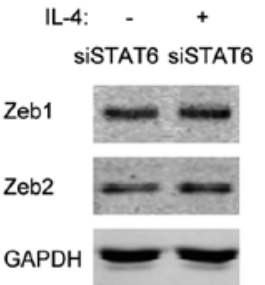

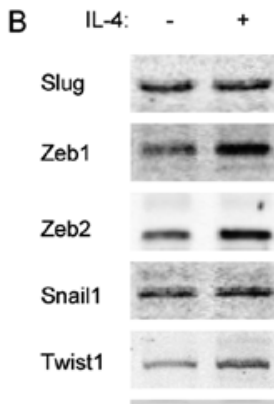

GAPDH

E
IL-4: siCtrl siSTAT6 siSTAT6 EV EV Zeb1

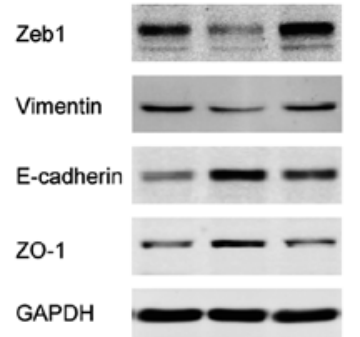

Figure 5. As a target gene of STAT6, Zeb1 is important in EMT triggered by IL-4. (A) mRNA levels of EMT transcription factors in HCT116 cells treated with $20 \mathrm{ng} / \mathrm{ml} \mathrm{IL}-4$ for $24 \mathrm{~h}$. (B) Western blots of the indicated proteins with specific antibodies in HCT116 cells treated with $20 \mathrm{ng} / \mathrm{ml} \mathrm{IL}-4$ for $24 \mathrm{~h}$. (C) mRNA levels of Zeb1/2 in HCT116 cells with STAT6-knockdown. (D) Western blots of the indicated proteins with specific antibodies in HCT116 cells transfected with STAT6 siRNA and exposed to $20 \mathrm{ng} / \mathrm{ml}$ IL-4 for $24 \mathrm{~h}$. (E) Western blots of the indicated proteins with specific antibodies in HCT116 cells co-transfected with STAT6 siRNA/Zeb1 overexpression plasmid and exposed to $20 \mathrm{ng} / \mathrm{ml} \mathrm{IL-4}$ for $48 \mathrm{~h}$. "P $<0.05 ;{ }^{* *} \mathrm{P}<0.01$. STAT6, signal transducer and activator of transcription 6; EMT, epithelial-mesenchymal transition; IL, interleukin; Zeb, zinc finger E-box-binding homeobox; si, small interfering; Ctrl, control; E-cadherin, epithelial cadherin; ZO-1, zonula occludens-1; EV, empty vector.
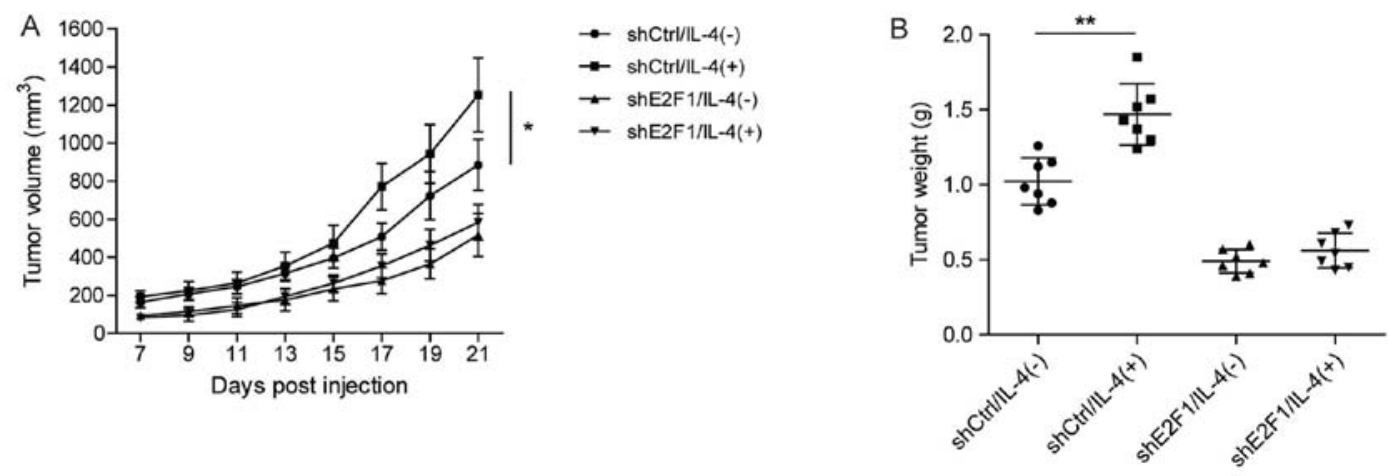

C shCtri shE2F1
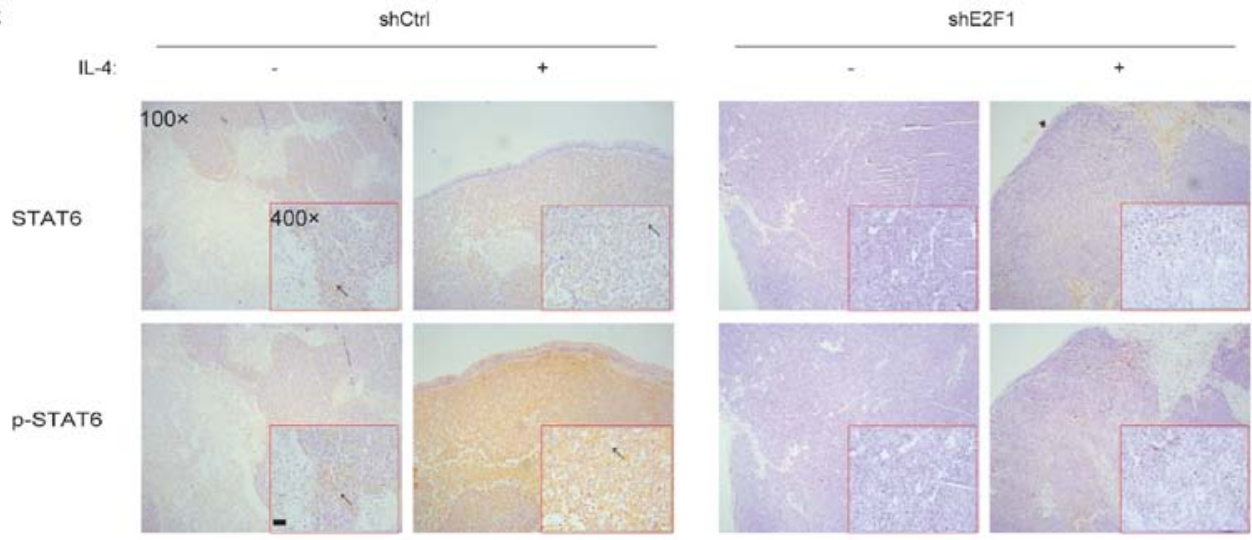

Figure 6. E2F1 is required for IL-4-induced CRC tumorigenesis in vivo. (A) Growth curves of the tumors formed by the indicated HCT116 cells. Results are presented as the mean $\pm \mathrm{SD}$ ( $\mathrm{n}=7$ mice per group). (B) Weight differences in tumors formed by the indicated HCT116 cells. Results are presented as the mean \pm SD ( $n=7$ mice per group). (C) Immunohistochemical staining of STAT6 and p-STAT6 proteins in the indicated xenograft tissues. Scale bar, $500 \mu \mathrm{m}$. The arrow indicates positive cells. "P<0.05. IL, interleukin; CRC, colorectal cancer; SD, standard deviation; sh, short hairpin RNA; Ctrl, control; STAT6, signal transducer and activator of transcription $6 ; \mathrm{p}-$, phosphorylated. 
Table II. Correlation of the expression of SP3, E2F1 and STAT6 with clinicopathological features in CRC.

\begin{tabular}{|c|c|c|c|c|c|c|c|c|c|c|}
\hline \multirow[b]{2}{*}{ Characteristic } & \multirow[b]{2}{*}{ Total } & \multicolumn{3}{|c|}{ SP3 expression } & \multicolumn{3}{|c|}{ E2F1 expression } & \multicolumn{3}{|c|}{ STAT6 expression } \\
\hline & & Low & High & P-value & Low & High & P-value & Low & High & P-value \\
\hline $\mathrm{N}$ & 218 & 103 & 115 & & 111 & 107 & & 113 & 105 & \\
\hline Tumor location & & & & 0.5832 & & & 0.7549 & & & 0.6933 \\
\hline Colon & 90 & 41 & 49 & & 44 & 46 & & 46 & 44 & \\
\hline Rectum & 128 & 62 & 66 & & 67 & 61 & & 67 & 61 & \\
\hline Sex & & & & 0.9837 & & & 0.3220 & & & 0.1288 \\
\hline Male & 116 & 56 & 60 & & 54 & 62 & & 54 & 62 & \\
\hline Female & 102 & 47 & 55 & & 57 & 45 & & 59 & 43 & \\
\hline Age, years & & & & 0.8908 & & & 0.7756 & & & 0.6932 \\
\hline$\leq 65$ & 88 & 43 & 45 & & 44 & 44 & & 46 & 42 & \\
\hline$>65$ & 130 & 60 & 70 & & 67 & 63 & & 67 & 63 & \\
\hline Differentiation status & & & & 0.9279 & & & 0.1521 & & & 0.6771 \\
\hline Well & 46 & 24 & 22 & & 22 & 24 & & 25 & 21 & \\
\hline Moderate & 147 & 68 & 79 & & 82 & 65 & & 78 & 69 & \\
\hline Poor & 25 & 11 & 14 & & 7 & 18 & & 10 & 15 & \\
\hline Tumor size, $\mathrm{cm}$ & & & & 0.2307 & & & 0.3672 & & & 0.3444 \\
\hline$<5$ & 105 & 46 & 59 & & 55 & 50 & & 50 & 55 & \\
\hline$\geq 5$ & 113 & 57 & 56 & & 56 & 57 & & 63 & 50 & \\
\hline Lymph node metastasis & & & & $0.0194^{\mathrm{a}}$ & & & 0.0957 & & & $0.0079^{\mathrm{a}}$ \\
\hline NO & 125 & 67 & 58 & & 70 & 55 & & 71 & 54 & \\
\hline N1 & 69 & 28 & 41 & & 33 & 36 & & 35 & 34 & \\
\hline $\mathrm{N} 2$ & 24 & 8 & 16 & & 8 & 16 & & 7 & 17 & \\
\hline TNM & & & & $0.0055^{\mathrm{a}}$ & & & $0.0126^{\mathrm{a}}$ & & & $0.0439^{\mathrm{a}}$ \\
\hline I & 35 & 20 & 15 & & 19 & 16 & & 17 & 18 & \\
\hline II & 83 & 39 & 44 & & 43 & 40 & & 50 & 33 & \\
\hline III & 83 & 41 & 42 & & 45 & 38 & & 41 & 42 & \\
\hline IV & 17 & 3 & 14 & & 4 & 13 & & 5 & 12 & \\
\hline Distant metastasis & & & & $0.0005^{\mathrm{a}}$ & & & $0.0010^{\mathrm{a}}$ & & & $0.0089^{\mathrm{a}}$ \\
\hline M0 & 201 & 102 & 99 & & 107 & 94 & & 114 & 87 & \\
\hline M1 & 17 & 3 & 14 & & 4 & 13 & & 5 & 12 & \\
\hline
\end{tabular}

${ }^{\text {ap }}<0.05$. TNM, tumor-node-metastasis.

CR-CSC cells, resistance to oxaliplatin is dependent on autocrine production of IL-4 (27). In the present study, the acquired EMT-like characteristics of several CRC cell lines stimulated by IL-4 were identified. However, it was observed that different CRC cell lines (HCT116 and RKO) with different expression levels of STAT6 exhibited entirely different responses to IL-4. As a key signaling transducer in the IL-4 pathway, STAT6 may determine the IL-4-induced aggressiveness of CRC cells. Consistent with this, it was identified previously that a lack of STAT6 attenuates inflammation and prevents early steps of colitis-associated CRC (28). Furthermore, HT-29 cells with an active STAT6 phenotype exhibit more aggressive metastasis compared with Caco-2 cells with defective STAT6 (29). Additionally, knockdown of STAT6 inhibits proliferation and induces apoptosis in HT-29 cells (30). Therefore, the STAT6 level may determine the $\mathrm{CRC}$ development facilitated by inflammatory cytokines.
Our previous study focused on E2F1, a critical transcription factor for CRC development, which promoted the migration and invasion of CRC cells (18). In the present study, it was identified that the levels of STAT6 protein were paralleled with E2F1 in several CRC cell lines. Further in vitro experiments confirmed an E2F1-dependent transcription of STAT6. However, no evident enrichment of E2F1 into the E2F1-response region located at the STAT6 promoter was identified in HCT116 with increased expression of STAT6, indicating an indirect regulation for STAT6 by E2F1. In addition, SP3, a member of the SP transcription factor family, was verified to mediate the transcription of the STAT6 gene. SP transcription factors including SP3 are have been identified to be overexpressed in tumors, whereas SP levels are relatively low in non-tumor tissues (31). Functional studies have identified that SP transcription factors have a function in cancer cell proliferation, survival, angiogenesis, migration and invasion by inducing oncogenes including 
A

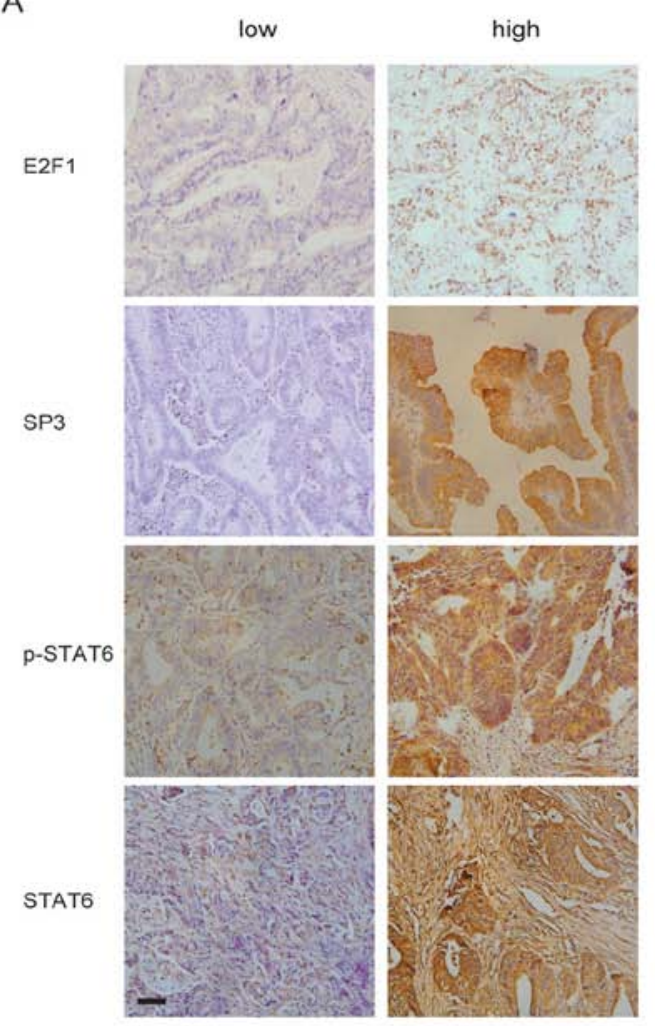

B
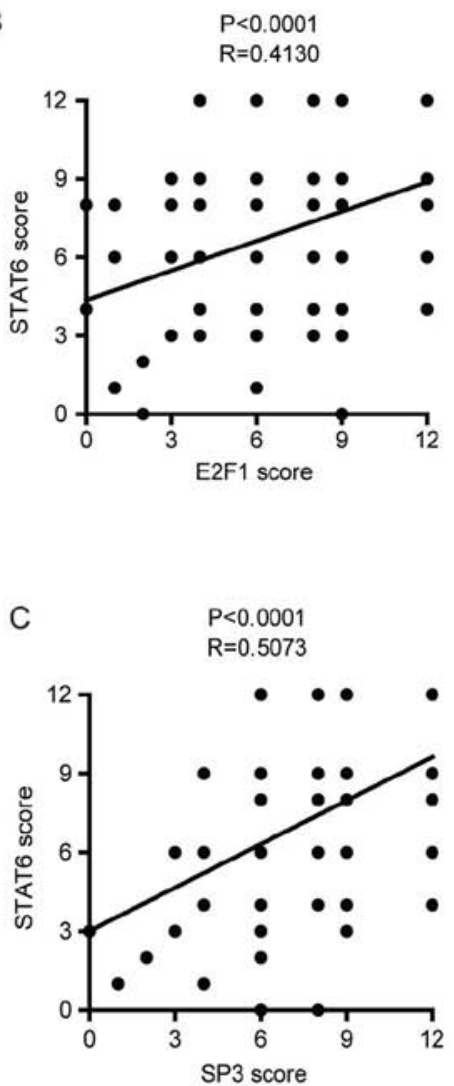

D

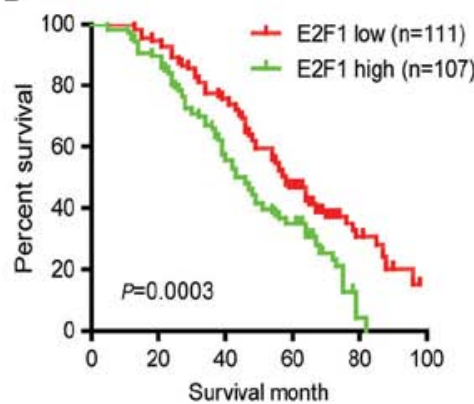

E

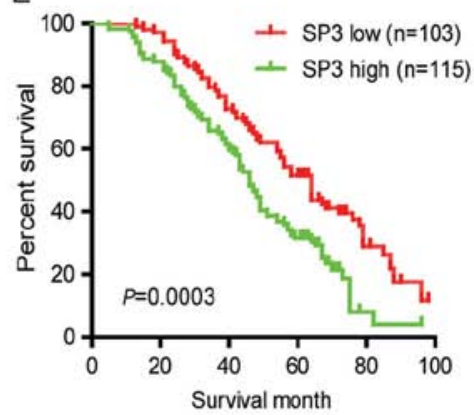

F

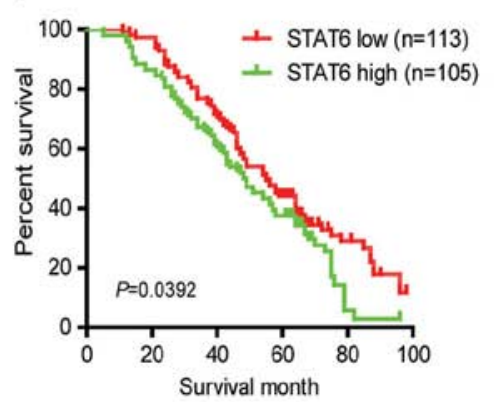

Figure 7. Abnormal activation of E2F1/SP3/STAT6 axis is associated with cancer malignancy in CRC samples. (A) Representative images of E2F1, SP3, p-STAT6 and STAT6 immunostaining in human CRC tissues. Scale bar, $200 \mu \mathrm{m}$. (B) Linear regression between immunostaining intensity of E2F1 and STAT6. (C) Linear regression between immunostaining intensity of SP3 and STAT6. Overall survival of patients with low and high expression of (D) E2F1,

(E) SP3 or (F) STAT6. SP3, specificity protein 3; STAT6, signal transducer and activator of transcription 6; CRC, colorectal cancer; p-, phosphorylated.

survivin, B-cell lymphoma 2, p65 (NF-кB), c-MET, EGFR and other receptor tyrosine kinases (32). The overexpressed SP members in CRC cells, SP1 and SP3, are required for migration and invasion (33). Even though SP1 and SP3 share $>90 \%$ DNA sequence homology in the DNA-binding domain and bind to the same DNA element with similar affinity (34), it was identified in the present study that SP3 rather than SP1 contributed to the transcription activation of the STAT6 gene in CRC cells. More importantly, increased expression of SP3 appeared to depend on E2F1, suggesting the E2F1/SP3/STAT6 axis as a potential regulatory pathway for STAT6 signaling in CRC. However, the reasons for SP3, but not SP1, being the major regulatory activator of the transcription of the STAT6 gene remain to be determined, and the details of how E2F1 regulates SP3 remain unknown.
On the surface of many solid tumors, IL-4R consists of the IL-4R $\alpha$ and IL-13R $\alpha 1$ subunits. Thus, IL-4R may be bound and activated by IL-13, although IL-4 binds with higher affinity (35). Previous studies demonstrate that IL-4 and IL-13 share signaling events by initiating a signaling cascade that activates the JAK/STAT pathway (particularly STAT6) in human CRC cells (36). Recent study by Cao et al (22) identified that IL-13/STAT6 signaling induces the aggressive properties of HT29 and SW480 cells through transactivating Zeb1, which is a well-known EMT core regulator and triggers malignant transformation. Therefore, in the present study, the expression patterns of EMT-associated transcription factors, including Snail1, Slug, Zeb1, Zeb2 and Twist1, were also investigated. However, the results of the present study were not completely consistent with those of 


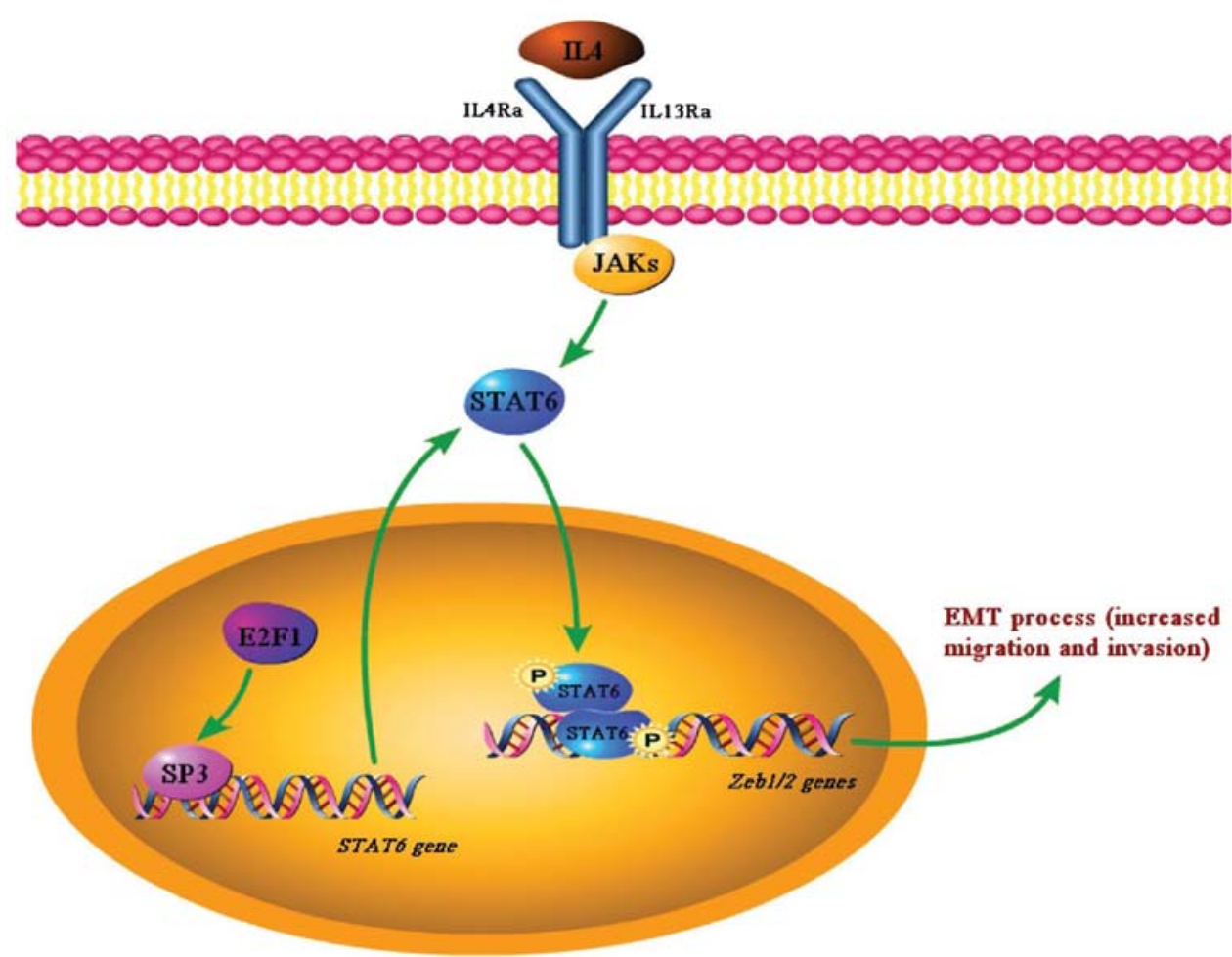

Figure 8. Schema indicating the crucial function of the E2F1/SP3/STAT6 axis in IL-4-induced EMT. In IL-4-responsive CRC cells such as HCT116, highly expressed E2F1 induces the expression of SP3, which transactivates STAT6. At the same time, IL-4 signaling leads to STAT6 phosphorylation, which then promotes the EMT of CRC cells by activating the transcription of Zeb1/2. SP3, specificity protein 3; STAT6, signal transducer and activator of transcription 6; IL, interleukin; EMT, epithelial-mesenchymal transition; CRC, colorectal cancer; Zeb, zinc finger E-box-binding homeobox; IL4Ra, IL-4 receptor $\alpha$; IL13R $\alpha$, IL-13 receptor $\alpha$; JAK, Janus kinase.

Cao et al (22), as demonstrated by the critical function of Zeb2 in the EMT progress driven by IL-4/STAT6 signaling. Despite STAT6 functioning as the common transducer in IL-4 and IL-13 signaling, activated STAT6 induces different expression profiles of downstream EMT-drivers following IL-4 and IL-13 stimulation.

In summary, we propose a model in which the high expression of STAT6 arose from abnormal activation of the E2F1/SP3/STAT6 axis and is phosphorylated by IL-4 and then promotes EMT progression by upregulating Zeb1/2, therefore enhancing the migration and invasion of CRC cells (Fig. 8). The discovery of such a regulatory pathway for IL-4 signaling suggests the potential of the E2F1/SP3/STAT6 axis to serve as a biomarker and represents a promising target for therapeutic intervention against CRC.

\section{Acknowledgements}

Not applicable.

\section{Funding}

The present study was supported by the Zhejiang Medical and Health Science and Technology Plan (grant no. 2018KY920) and the Taizhou Science and Technology Plan (1601KY61). It was also supported by the Zhejiang Medical and Health Science and Technology Plan (grant nos. 2018KY184, 2016KYB330 and 2017KY722) and the Science and Technology Program of Sanmen County Public Technology Social Development Project (grant nos. 16302, 16304 and 16312).

\section{Availability of data and materials}

All data generated or analyzed during this study are included in this published article.

\section{Authors' contributions}

HL and XC conceived and designed the study. JC, CG, HM, ZL, ZF, QC, ML, XJ, YH, WW, XZ, XC and HL performed the experiments and wrote the manuscript. JC, CG, HM, ZL and ZF analyzed and interpreted data. JC, HL, XC, ZF and WW contributed reagents and materials. All authors helped to draft the manuscript and read and approved the final manuscript.

\section{Ethics approval and consent to participate}

Experiments using human tissues were performed with the approval of the Ethics Committee of Sanmen People's Hospital (Sanmen, China). Animal experiments were performed with the approval of the Ethics Committee of Sanmen People's Hospital and the Animal Care and Use Committee of Zhejiang University (Hangzhou, China).

\section{Patient consent for publication}

Not applicable.

\section{Competing interests}

The authors declare that they have no competing interests. 


\section{References}

1. Sears CL and Garrett WS: Microbes, microbiota, and colon cancer. Cell Host Microbe 15: 317-328, 2014.

2. Todaro M, Gaggianesi M, Catalano V, Benfante A, Iovino F, Biffoni M, Apuzzo T, Sperduti I, Volpe S, Cocorullo G, et al: $\mathrm{CD} 44 \mathrm{v} 6$ is a marker of constitutive and reprogrammed cancer stem cells driving colon cancer metastasis. Cell Stem Cell 14: 342-356, 2014.

3. Terzić J, Grivennikov S, Karin E and Karin M: Inflammation and colon cancer. Gastroenterology 138: 2101-2114.e5, 2010.

4. Shawki S, Ashburn J, Signs SA and Huang E: Colon cancer: Inflammation-associated cancer. Surg Oncol Clin N Am 27: 269-287, 2018.

5. Wang $\mathrm{K}$ and Karin M: Tumor-elicited inflammation and colorectal cancer. Adv Cancer Res 128: 173-196, 2015.

6. Ullman TA and Itzkowitz SH: Intestinal inflammation and cancer. Gastroenterology 140: 1807-1816, 2011.

7. Waldner MJ, Foersch S and Neurath MF: Interleukin-6 - a key regulator of colorectal cancer development. Int J Biol Sci 8: 1248-1253, 2012

8. Lee YS, Choi I, Ning Y, Kim NY, Khatchadourian V, Yang D, Chung HK, Choi D, LaBonte MJ, Ladner RD, et al: Interleukin-8 and its receptor CXCR2 in the tumour microenvironment promote colon cancer growth, progression and metastasis. Br J Cancer 106: 1833-1841, 2012.

9. Barderas R, Bartolomé RA, Fernandez-Aceñero MJ, Torres S and Casal JI: High expression of IL-13 receptor $\alpha 2$ in colorectal cancer is associated with invasion, liver metastasis, and poor prognosis. Cancer Res 72: 2780-2790, 2012.

10. Hyun YS, Han DS, Lee AR, Eun CS, Youn J and Kim HY: Role of IL-17A in the development of colitis-associated cancer. Carcinogenesis 33: 931-936, 2012.

11. Kanai T, Watanabe M, Hayashi A, Nakazawa A, Yajima T, Okazawa A, Yamazaki M, Ishii $\mathrm{H}$ and Hibi T: Regulatory effect of interleukin-4 and interleukin-13 on colon cancer cell adhesion. Br J Cancer 82: 1717-1723, 2000.

12. Koller FL, Hwang DG, Dozier EA and Fingleton B: Epithelial interleukin-4 receptor expression promotes colon tumor growth Carcinogenesis 31: 1010-1017, 2010.

13. Bankaitis KV and Fingleton B: Targeting IL4/IL4R for the treatment of epithelial cancer metastasis. Clin Exp Metastasis 32: $847-856,2015$

14. Di Stefano AB, Iovino F, Lombardo Y, Eterno V, Höger T, Dieli F, Stassi G and Todaro M: Survivin is regulated by interleukin-4 in colon cancer stem cells. J Cell Physiol 225: 555-561, 2010.

15. Liu H, Antony S, Roy K, Juhasz A, Wu Y, Lu J, Meitzler JL, Jiang G, Polley E and Doroshow JH: Interleukin-4 and interleukin-13 increase NADPH oxidase 1-related proliferation of human colon cancer cells. Oncotarget 8: 38113-38135, 2017.

16. Alla V, Engelmann D, Niemetz A, Pahnke J, Schmidt A, Kunz M, Emmrich S, Steder M, Koczan D and Pützer BM: E2F1 in melanoma progression and metastasis. J Natl Cancer Inst 102: $127-133,2010$

17. Hsu EC, Kulp SK, Huang HL, Tu HJ, Chao MW, Tseng YC, Yang MC, Salunke SB,Sullivan NJ, Chen WC, et al: Integrin-linked kinase as a novel molecular switch of the IL-6-NF- $\kappa \mathrm{B}$ signaling loop in breast cancer. Carcinogenesis 37: 430-442, 2016.

18. Fang Z, Gong C, Liu H, Zhang X, Mei L, Song M, Qiu L, Luo S, Zhu Z,Zhang R, et al: E2F1 promote the aggressiveness of human colorectal cancer by activating the ribonucleotide reductase small subunit M2. Biochem Biophys Res Commun 464: 407-415, 2015

19. Livak KJ and Schmittgen TD: Analysis of relative gene expression data using real-time quantitative PCR and the 2(-Delta Delta C(T)) method. Methods 25: 402-408, 2001

20. Fang Z, Gong C, Yu S, Zhou W, Hassan W, Li H, Wang X, Hu Y, $\mathrm{Gu} \mathrm{K}$, Chen X, et al: NFYB-induced high expression of E2F1 contributes to oxaliplatin resistance in colorectal cancer via the enhancement of CHK1 signaling. Cancer Lett 415: 58-72, 2018.
21. Formentini A, Braun P, Fricke H, Link KH, Henne-Bruns D and Kornmann M: Expression of interleukin-4 and interleukin-13 and their receptors in colorectal cancer. Int J Colorectal Dis 27: 1369-1376, 2012.

22. Cao H, Zhang J, Liu H, Wan L, Zhang H, Huang Q, Xu E and Lai M: IL-13/STAT6 signaling plays a critical role in the epithelialmesenchymal transition of colorectal cancer cells. Oncotarget 7: 61183-61198, 2016.

23. Cavallo F, De Giovanni C, Nanni P, Forni G and Lollini PL: 2011: The immune hallmarks of cancer. Cancer Immunol Immunother 60: 319-326, 2011.

24. Prokopchuk O, Liu Y, Henne-Bruns D and Kornmann M: Interleukin-4 enhances proliferation of human pancreatic cancer cells: Evidence for autocrine and paracrine actions. Br J Cancer 92: 921-928, 2005.

25. Conticello C, Pedini F, Zeuner A, Patti M, Zerilli M, Stassi G, Messina A, Peschle C andDe Maria R: IL-4 protects tumor cells from anti-CD95 and chemotherapeutic agents via up-regulation of antiapoptotic proteins. J Immunol 172: 5467-5477, 2004.

26. Todaro M, Zerilli M, Ricci-Vitiani L, Bini M, Perez Alea M, Maria Florena A, Miceli L, Condorelli G, Bonventre S, Di Gesù G, et al: Autocrine production of interleukin- 4 and interleukin- 10 is required for survival and growth of thyroid cancer cells. Cancer Res 66: 1491-1499, 2006.

27. Todaro M, Alea MP, Di Stefano AB, Cammareri P, Vermeulen L, Iovino F, Tripodo C, Russo A, Gulotta G, Medema JP, et al: Colon cancer stem cells dictate tumor growth and resist cell death by production of interleukin-4. Cell Stem Cell 1: 389-402, 2007.

28. Leon-Cabrera SA, Molina-Guzman E, Delgado-Ramirez YG, Vázquez-Sandoval A, Ledesma-Soto Y, Pérez-Plasencia CG, Chirino YI, Delgado-Buenrostro NL, Rodríguez-Sosa M, Vaca-Paniagua F, et al: Lack of STAT6 attenuates inflammation and drives protection against early steps of colitis-associated colon cancer. Cancer Immunol Res 5: 385-396, 2017.

29. Li BH, Yang XZ, Li PD, Yuan Q, Liu XH, Yuan J and Zhang WJ: IL-4/Stat6 activities correlate with apoptosis and metastasis in colon cancer cells. Biochem Biophys Res Commun 369: 554-560, 2008.

30. Zhang M, Zhou Y, Xie C, Zhou F, Chen Y, Han G and Zhang WJ: STAT6 specific shRNA inhibits proliferation and induces apoptosis in colon cancer HT-29 cells. Cancer Lett 243: 38-46, 2006.

31. Vizcaíno C, Mansilla S and Portugal J: Sp1 transcription factor: A long-standing target in cancer chemotherapy. Pharmacol Ther 152: 111-124, 2015.

32. Safe S, Imanirad P, Sreevalsan S, Nair V and Jutooru I: Transcription factor Sp1, also known as specificity protein 1 as a therapeutic target. Expert Opin Ther Targets 18: 759-769, 2014.

33. Hedrick E, Cheng Y, Jin UH, Kim K and Safe S: Specificity protein (Sp) transcription factors Sp1, Sp3 and Sp4 are non-oncogene addiction genes in cancer cells. Oncotarget 7: 22245-22256, 2016

34. Wierstra I: Sp1: emerging roles - beyond constitutive activation of TATA-less housekeeping genes. Biochem Biophys Res Commun 372: 1-13, 2008.

35. LaPorte SL, Juo ZS, Vaclavikova J, Colf LA, Qi X, Heller NM, Keegan AD and Garcia KC: Molecular and structural basis of cytokine receptor pleiotropy in the interleukin-4/13 system. Cell 132: 259-272, 2008.

36. Murata T, Noguchi PD and Puri RK: IL-13 induces phosphorylation and activation of JAK2 Janus kinase in human colon carcinoma cell lines: similarities between IL-4 and IL-13 signaling. J Immunol 156: 2972-2978, 1996.

This work is licensed under a Creative Commons Attribution-NonCommercial-NoDerivatives 4.0 International (CC BY-NC-ND 4.0) License. 